\title{
Disturbances of apoptotic cell clearance in systemic lupus erythematosus
}

\author{
Wen-Hai Shao and Philip L Cohen*
}

\begin{abstract}
Systemic lupus erythematosus is a multifactorial autoimmune disease with an as yet unknown etiopathogenesis. It is widely thought that selfimmunization in systemic lupus is driven by defective clearance of dead and dying cells. In lupus patients, large numbers of apoptotic cells accumulate in various tissues including germinal centers. In the present review, we discuss the danger signals released by apoptotic cells, their triggering of inflammatory responses, and the breakdown of B-cell tolerance. We also review the pathogenic role of apoptotic cell clearance in systemic lupus erythematosus.
\end{abstract}

\section{Introduction}

Cell death is a necessary and natural process that occurs under both physiological and pathological conditions in all tissues. This process is also a critical mechanism in immune tolerance and in contraction of normal immune responses to exogenous antigens. Apoptosis is the predominant pathway for cell death, but cells can also undergo death through necrosis and necroptosis, a programmed cell death independent of caspase activation [1]. Apoptotic cells must be quickly removed from tissues so that they elicit neither inflammation nor immune responses. Inefficient clearance of apoptotic cells and subsequent accumulation of apoptotic cell debris provoke a chronic inflammatory response and may lead to breakdown of self-tolerance [2].

Autoimmunity in systemic lupus erythematosus (SLE) is believed to be driven by autoantigens. Certain key autoantigens are demonstrable on blebs of apoptotic cells. Considerable evidence supports the notion that SLE autoimmunity could be related to impaired or delayed clearance of apoptotic cells. Persistent apoptotic cells

*Correspondence: philco@temple.edu

Section of Rheumatology, Department of Medicine, Temple University, 3322 North Broad Street, Room 205, Philadelphia, PA 19140, USA may progress to secondary necrotic cell death, a process associated with danger signals, accessible modified autoantigens, and initiation of autoimmune reactions.

\section{Clearance of apoptotic cells}

Efficient recognition and clearance of apoptotic cells involve many ligands, receptors, and bridging molecules between dying cells and phagocytes. In vitro studies have indicated that this process is tightly controlled and remarkably complex.

Early apoptotic cells express eat-me signals through asymmetric distribution of aminophospholipids such as phosphatidylserine (PS), phosphatidylethanolamine, and phosphatidylcholine to the outer leaflet. PS is the bestcharacterized eat-me signal, and externalization of PS alone is efficient enough to initiate the engulfment of apoptotic cells by macrophages (M $\phi s)$ [3]. In addition, apoptotic cells actively secrete chemoattractant factors known as find-me signals to the environment to attract phagocytes, such as M $\phi$ s and dendritic cells (DCs). The covalent dimer of ribosomal protein S19 was the first identified find-me signal of apoptotic cells [4], but its mechanism of action is still unclear. Apoptotic thymocytes release nucleotides (ATP and UTP) in a caspasedependent manner to attract monocytes [5], so that release of nucleotides can be blocked by the caspase inhibitor zVAD-fmk. A diverse find-me signal has been identified and is reviewed elsewhere [6]. Interestingly, a recent study reported that the 75 to $80 \mathrm{kDa}$ iron-binding protein lactoferrin could serve as an anti-attraction (keep-out) signal by different apoptotic cell lines. Lactoferrin mediates strong inhibition of neutrophil migration but not $\mathrm{M} \phi$ migration [7]. SIRP- $\alpha$, another keep-out signal, was reported by Tsai and Discher [8]. CD47-SIRP- $\alpha$ signaling negatively regulates phagocytosis through inhibition of the downstream signaling events of phagocytic receptors. Loss of function or blocking of either molecule causes removal of viable cells that are not normally phagocytosed [9].

Recognition and binding of find-me signals on the apoptotic cells initiate the engulfment of apoptotic cells. Receptors such as CD36, scavenger receptor A, and PS receptor can directly bind to the eat-me molecules and 
initiate phagocytosis, while other receptors require the help of bridging molecules (reviewed in $[10,11]$ ). Tyro-3, Axl, and Mertk (TAM) receptor tyrosine kinases bind to apoptotic cells with the aid of two vitamin K-dependent factors, growth arrest specific protein 6 and protein $S$ $[12,13]$. Mice lacking Mertk have impaired clearance of apoptotic cells and develop lupus-like autoimmunity, while TAM triple-knockout mice suffer from more severe disease $[14,15]$. These mice develop a systemic autoimmune disorder with swollen joints and footpads, skin lesions, and glomerular immune complex deposition. A broad spectrum of autoantibodies is detectable in the serum. TAM receptor signaling normally not only facilitates apoptotic clearance, but also downregulates proinflammatory $\mathrm{M} \phi \mathrm{s}$ and DCs. Activation of TAM receptor signals leads to a broad inhibition of Toll-like receptor (TLR)-induced cytokines through the IFNARSTAT1 cassette to induce TLR suppressors SOCS1 and SOCS3 [16].

Defective clearance of apoptotic cells can result in accumulation of apoptotic debris. In the thymus and bone marrow, most developing $\mathrm{T}$ cells and $\mathrm{B}$ cells undergo apoptosis due to failure of positive and negative selection. Those apoptotic cells have to be cleared efficiently in a non-inflammatory way. Tisch and colleagues demonstrated a key role of Mertk on T-cell central tolerance by enhancing negative selection of autoreactive $\mathrm{T}$ cells specific for pancreatic $\beta$ cells [17]. Nonobese diabetic mice lacking Mertk failed to develop diabetes due to an increased thymic negative selection of $\beta$-cell-specific $\mathrm{T}$ cells and an increased capacity of DCs to induce thymocyte apoptosis [17].

In germinal centers, clonal selection of high-affinity $B$ cells results in large numbers of apoptotic cells, including autoreactive cells. Clearance of these cells is essential to maintain peripheral tolerance. Specialized phagocytes that clear dying cells are referred to as tingible body macrophages (TBM $\phi s)$ in the germinal center. Nagata's group revealed a critical role of milk fat globule epidermal growth factor 8 (MFG-E8) in integrin-mediated TBM $\phi$ phagocytosis of apoptotic cells [18]. MFG-E8 promotes the phagocytosis of apoptotic cells by serving as a bridging molecule between apoptotic cells and phagocytes. Without MFG-E8, mice developed autoimmune disease associated with defective apoptotic cell clearance in the germinal center. Alternatively, when apoptotic cell clearance was disturbed with MFG-E8 mutant protein D89E, autoantibodies against phospholipids and nuclear proteins were induced in mice [19]. Later, the same group reported a reduced level of MFG-E8 in some childhood-onset and adult SLE patients and a dosedependent inhibition of $\mathrm{M} \phi$ uptake of apoptotic cells by human MFG-E8 [20]. Aberrant splicing of MFG-E8 was also reported in SLE patients. Repeated administration of the same mutant MFG-E8 into mice induced anticardiolipin and antinuclear autoantibodies [21]. Similarly, we discovered a primary role of Mertk on TBM $\phi$ clearance of apoptotic B cells in the germinal center. Large numbers of apoptotic bodies accumulated outside TBM $\phi$ s in Mertk $^{-1-}$ mice immunized with NP-chicken $\gamma$ globulin [22].

The T-cell immunoglobulin mucin (TIM) gene family has recently been shown crucial for clearance of apoptotic cells, autoimmune regulation, and tolerance induction. Tim- 1 and Tim- 4 specifically bound PS on the surface of apoptotic cells [23]. Tim- $4^{-/-}$mice show defects in apoptotic cell clearance by peritoneal $\mathrm{M} \phi \mathrm{s}$ and B-1 cells. Tim $-4^{-/-}$mice develop autoantibodies against dsDNA associated with hyperreactive $T$ cells and $B$ cells [24]. Tim-3, on the other hand, recognizes apoptotic cells via the FG loop in the IgV domain. Inhibition of apoptotic cell engulfment by $\mathrm{CD}^{+}$DCs through anti-Tim-3 mAb results in reduced autoantigen cross-presentation in vivo and in vitro. Administration of Tim-3 and Tim- 4 mAb induces autoantibody production in animals [25].

\section{Danger signals from later apoptotic cells/necrotic cells}

Phagocytic clearance of apoptotic cells can influence immune responses dramatically by enhancing or suppressing inflammation, depending on additional immune stimuli (Figure 1). DCs may present self-derived antigen if appropriate danger signals are provided. Defective or prolonged clearance of apoptotic cells allows them to progress to secondary necrosis, a stage where danger signals may accumulate. Our knowledge about danger signals released from apoptotic cells, however, is rather limited. Nucleic acid, proteins, inflammatory cytokines, and metabolic intermediates are all well-accepted danger signals in other contexts [26]. We highlight recently described key danger signals in the present review.

\section{High mobility group box 1 protein}

High mobility group box 1 (HMGB1) is an evolutionary conserved ubiquitously expressed chromosomal protein consisting of two positively charged DNA binding domains, called HMG boxes A and B.

HMGB1 binds to and helps to stabilize dsDNA, ssDNA, distorted DNA, and nucleosomes. HMGB1 can be actively secreted from living cells and passively secreted from dying cells during late apoptosis and necrosis (reviewed in [27]). HMGB1 released from apoptotic cells undergoes post-translational oxidative modification and acts as a proinflammatory mediator [28]. HMGB1 has been found to be elevated significantly in sera from lupus patients [28]. The precise pathophysiological role of HMGB1 in lupus, however, remains to be further elucidated. In UV-induced skin lesions of 


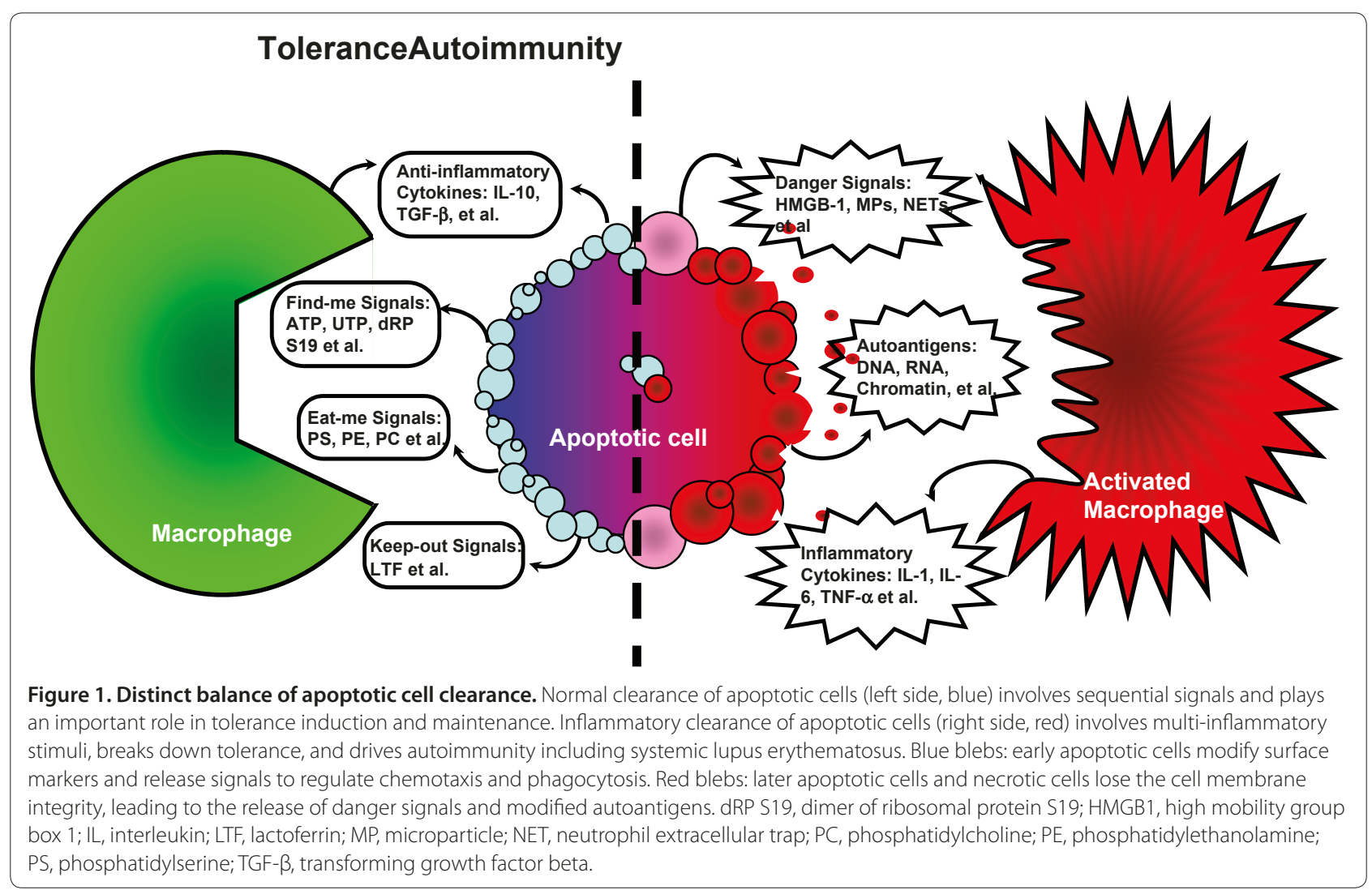

experimental cutaneous lupus, HMGB1 increased coincident with clinical activity [29,30]. HMGB1 can interfere with apoptotic clearance by blocking cell surface PS, causing accumulation of apoptotic cells and worsening disease. HMGB1 can also increase production of IFN $\alpha$ by plasmacytoid DCs through TLR9 and RAGE, or of cytokines from activated B cells through TLR2. HMGB1 has been identified as an autoantigen in lupus patients, and thus may itself be a target in autoimmune responses. Anti-HMGB1 autoantibodies are positively correlated with the SLE disease activity index [31]. Patients shown to have positive autoantibodies for HMGB1 presented with significantly higher SLE disease activity index values.

\section{Microparticles}

Microparticles (MPs), also known as plasma membranederived vesicles, are small membrane-bound vesicles released from dying cells via blebbing and shedding. MPs incorporate cytoplasmic proteins such as cytokines, growth factors, acute phase proteins, and DNA and RNA.

Increased numbers of plasma MPs have been documented in SLE patients with secondary anti-phospholipid syndrome [32,33]. Pisetsky and Lipsky proposed an autoadjuvant model for MPs as a revised version of the waste disposal hypothesis of SLE [34]. In this model, nucleic-acid-containing MPs act as autoadjuvants in both central tolerance and peripheral B-cell activation in normal individuals. MPs loaded with DNA and RNA enhance their stimulatory capacity and ensure effective central deletion during B-cell development. In individuals with SLE, MP may particularly promote the survival of DNA-specific and RNA-specific autoreactive B cells due to their effectiveness in stimulating $B$ cells through their immunoglobulin receptors. Recently, Antwi-Baffour and colleagues revealed a dose-dependent competition of MPs with apoptotic cells for PS receptor on M $\phi$ s [35]. The fact that MPs express high concentrations of PS on their outer leaflet makes them potent inhibitors of phagocytosis of normal apoptotic cells. This may result in secondary necrosis and subsequent increase of apoptotic debris.

To our knowledge, there is no universally accepted definition for MPs. A wide range of MP sizes (0.02 to $2 \mu \mathrm{m})$ has been reported by different groups in the literature [34,36]. MPs bear many surface adhesion molecules, making them likely to adhere to leukocytes or endothelial cells. This and other physical characteristics of MPs add to difficulties in their quantitative analysis, emphasizing the need for attention to collecting, processing, and storage of samples containing MPs. Flow cytometry-based assays are routinely used in the field, while electron or confocal microscopy may be better for 
visualization, characterization, and morphological study [36]. An ELISA-based assay was also developed for platelet-derived MPs by Osumi and colleagues [37].

\section{Neutrophil extracellular traps}

Neutrophil extracellular traps (NETs), extended chromatin networks released from activated neutrophils, constitute an intricate mechanism used by neutrophils to capture and kill invading microorganisms [38]. In SLE patients, neutrophils are activated and express genes induced by type I interferons $[39,40]$. SLE patients produce antibodies against NETs and against neutrophil proteins such as myeloperoxidase and proteinase-3 [41]. Impaired recognition and clearance of apoptotic neutrophils may due to reduced expression of CD44 on neutrophils in SLE [42]. NETs are made of DNA, histones, and neutrophil proteins. Timely removal of NETs is essential to avoid self-antigen presentation. Zychlinsky and colleagues found that impaired degradation of NETs in SLE patients correlates with lupus nephritis. Difficulty in NET clearance is due to the presence of DNase 1 inhibitors and prevention of DNase 1 access to NETs by anti-NET antibodies [39].

\section{DNase I}

DNase I facilitates chromatin breakdown during apoptosis and has been implicated in the pathophysiology of SLE since the 1950s. Lupus-prone NZB/NZW mice have significantly lower serum and urine concentrations of DNase I compared with normal mice [43], which may allow more immune complexes to persist in the kidney and further promote disease progression. An elegant study with the same model showed that reduced levels of renal DNase I coincided with deficient fragmentation of chromatin from dead cells, implying that the lack of this enzyme may have caused delayed clearance [44]. Furthermore, DNase-I-deficient mice developed a SLE-like syndrome with antinuclear antibodies, immune complex deposition, and glomerulonephritis [45]. Consistent with these findings, lower serum DNase I activity was demonstrated in SLE patients compared with patients with rheumatoid arthritis and scleroderma and compared with healthy controls $[45,46]$. In this regard, two DNaseI-deficient SLE patients with high serum titers of antidsDNA antibodies were reported [47]. Attempts to use DNase I as a therapeutic agent in SLE were carried out by several groups and were mildly encouraging $[48,49]$.

\section{Disturbed apoptotic cell clearance in SLE patients}

Much of the preceding evidence for apoptotic clearance impairment in SLE comes from mouse models of lupus. In human lupus, apoptotic cell bodies unengulfed by lymph node TBM $\phi$ s have been observed in vivo. Free apoptotic debris found attached to follicular DCs might provide survival signals to autoreactive B cells generated from random somatic hypermutation [50]. Significantly increased numbers of circulating endothelial cells in SLE patients have been interpreted to reflect an enhanced apoptotic rate, and possibly decreased clearance of these cells [51]. Freshly isolated or cultured lymphocytes from SLE patients showed a significantly increased fraction of cells undergoing apoptosis in comparison with normal control individuals or rheumatoid arthritis patients, with a correlation between SLE disease activity and the rate of in vitro apoptosis. Extracellular nucleosomes were also increased in proportion to the rate of apoptosis [52]. In juvenile-onset SLE, neutrophil apoptosis is significantly increased, and this is thought to be due to an imbalance in proapoptotic and antiapoptotic factors in both neutrophils and sera from the patients [53].

UVB has long been associated with apoptosis induction and lupus flares. Caricchio and colleagues revealed a dose-dependent immunological fate of UVB-induced apoptosis: non-inflammatory apoptosis from low-dose UVB, and proinflammatory apoptosis from higher-dose UVB [54]. Later, Reefman and colleagues compared the apoptotic/necrotic rate of 14 SLE patients with 16 controls in response to $200 \mathrm{MJ} / \mathrm{cm}^{2} \mathrm{UVB}$ irradiation. Although sensitivity of SLE to UVB was not related to the numbers of apoptotic or necrotic keratinocytes in the skin [55], UVB-induced skin lesions were associated with apoptotic keratinocytes [56]. In another study, Fas-mediated apoptosis was thought to account for the low numbers of bone marrow $\mathrm{CD}^{+} 3^{+}$cells in active SLE, although relatively small numbers of patients were studied [57].

An in vitro defect in apoptotic cell clearance has been described in SLE. M $\phi$ s cultured from SLE patients display morphological abnormalities with impaired phagocytosis of apoptotic cells [50,58]. M $\phi$ s derived from SLE monocytes or stem cells were smaller with less ability to differentiate and with impaired adhesion [58]. Moreover, sera from SLE patients possessed an enhanced capacity to induce apoptosis [59]. In this study, sera from 37 sex-matched and age-matched SLE patients and a total of 37 other autoimmune/infectious disease and healthy donors were sampled; the apoptosis-inducing effect of the sera on normal monocytes or lymphocytes was compared. The apoptosis-inducing effect was significantly higher in sera from SLE patients than controls. Subsequent studies showed that the SLE sera-induced apoptosis is caspase dependent but death receptor independent [60]. Although the apoptosis-inducing factor has not yet been identified, the existence of these factors may give rise to apoptotic cells in SLE and worsen the pathogenic condition. Interestingly, Dransfield and colleagues found that glucocorticoid-treated $\mathrm{M} \phi$ s have increased capacity to phagocyte apoptotic neutrophils, apparently due to enhanced protein $S$ signaling of the 
Mertk [61]. In this regard, we recently reported low levels of protein S in certain subsets of SLE patients [62]. Together, the data may support an important role of Mertk in the inefficient clearance of apoptotic cells in certain SLE patients. A follow-up investigation of levels of TAM receptors in SLE patients may help in understanding the distinct role of TAM receptors in the pathogenesis of SLE.

There are strong links between apoptotic clearance deficiency and SLE, yet no direct etiological role has been established for impairment of apoptotic clearance in human SLE. The initiating phase of SLE may be multifactorial and individually variable, while the presence of excessive apoptotic debris may have profound pathogenic relevance and correlation with disease activity. It has been shown that the presence of antinuclear antibodies, reactive with apoptotic debris, may render apoptotic cells proinflammatory and thus create a vicious cycle producing further autoantibodies and inflammation [63]. In this regard, the lupus erythematosus cell exemplifies this phenomenon of phagocytosis of autoantibody-coated apoptotic cells. Lupus erythematosus cells were discovered over 60 years ago, and the LE prep, where lupus white blood cells are observed to undergo spontaneous phagocytosis of debris in vitro, was the standard test for lupus until about 30 years ago [64].

\section{Conclusions}

Clearance of apoptotic cells is a daunting challenge to the immune system, which has multiple redundant receptorligand systems to efficiently eliminate senescent and superfluous apoptotic cells. It is now well established in animal models that this process may fall short under certain circumstances, leading to abnormally persistent and potentially immunogenic apoptotic and necrotic cells. Both in vivo and in vitro evidence supports the notion that certain human autoimmune diseases, particularly SLE, may also arise from impaired apoptotic cell clearance. Better understanding of the immunobiology of apoptotic cell clearance may lead to new therapeutic approaches to lupus and related autoimmune diseases.

Autoimmune Basis of Rheumatic Diseases

This article is part of a series on Systemic lupus erythematosus, edited by David Pisetsky, which can be found online at http://arthritis-research.com/series/lupus

This series forms part of a special collection of reviews covering major autoimmune rheumatic diseases, available at:

http://arthritis-research.com/series/abrd

\section{Abbreviations}

DC, dendritic cell; dsDNA, double-strand DNA; ELISA, enzyme-linked immunosorbent assay; HMGB1, high mobility group box 1; IFN, interferon;
$M \varphi$, macrophage; $m A b$, monoclonal antibody; Mertk, Mer receptor tyrosine kinase; MFG-E8, milk fat globule epidermal growth factor 8; MP, microparticle; NET, neutrophil extracellular trap; PS, phosphatidylserine; SLE, systemic lupus erythematosus; ssDNA, single-strand DNA; TAM, Tyro-3, Axl, and Mertk; TBM $\varphi$, tingible body macrophage; TIM, T-cell immunoglobulin mucin; TLR, Toll-like receptor; TNF, tumor necrosis factor; UVB, ultraviolet $B$.

\section{Competing interests}

The authors declare that they have no competing interests.

\section{Acknowledgements}

The authors are grateful for the helpful discussion from Dr Roberto Caricchio. The present work was supported by grants from the NIDCR (R01DE017590) and the US Department of Veterans Affairs to PLC and an Arthritis Foundation Postdoc Fellowship Award to W-HS.

Published: 28 February 2011

\section{References}

1. Declerca W, Vanden Berghe T, Vandenabeele P: RIP kinases at the crossroads of cell death and survival. Cell 2009, 138:229-232.

2. Munoz LE, Lauber K, Schiller M, Manfredi AA, Herrmann M: The role of defective clearance of apoptotic cells in systemic autoimmunity. Nat Rev Rheumatol 2010, 6:280-289.

3. Fadeel B, Xue D, Kagan V: Programmed cell clearance: molecular regulation of the elimination of apoptotic cell corpses and its role in the resolution of inflammation. Biochem Biophys Res Commun 2010, 396:7-10.

4. Horino K, Nishiura H, Ohsako T, Shibuya Y, Hiraoka T, Kitamura N, Yamamoto T: A monocyte chemotactic factor, S19 ribosomal protein dimer, in phagocytic clearance of apoptotic cells. Lab Invest 1998, 78:603-617.

5. Elliott MR, Chekeni FB, Trampont, P. C, Lazarowski, ER, Kadl A, Walk SF, Park D, Woodson RI, Ostankovich M, Sharma P, Lysiak JJ, Harden TK, Leitinger N, Ravichandran KS: Nucleotides released by apoptotic cells act as a find-me signal to promote phagocytic clearance. Nature 2009, 461:282-286.

6. Munoz LE, Peter C, Herrmann M, Wesselborg S, Lauber K: Scent of dying cells: the role of attraction signals in the clearance of apoptotic cells and its immunological consequences. Autoimmun Rev 2010, 9:425-430.

7. Bournazou I, Pound JD, Duffin R, Bournazos S, Melville LA, Brown SB, Rossi AG, Gregory CD: Apoptotic human cells inhibit migration of granulocytes via release of lactoferrin. J Clin Invest 2009, 119:20-32.

8. Tsai RK, Discher DE: Inhibition of 'self' engulfment through deactivation of myosin-Il at the phagocytic synapse between human cells. J Cell Bio/ 2008, 180:989-1003

9. Gardai SJ, MCPhillips KA, Frasch SC, Janssen WJ, Starefeldt A, Murphy-Ullrich JE, Bratton DL, Oldenborg PA, Michalak M, Henson PM: Cell-surface calreticulin initiates clearance of viable or apoptotic cells through transactivation of LRP on the phagocyte. Cell 2005, 123:321-334.

10. Ogden CA, Elkon KB: Role of complement and other innate immune mechanisms in the removal of apoptotic cells. Curr Dir Autoimmun 2006, 9:120-142

11. Cohen PL, Caricchio R: Genetic models for the clearance of apoptotic cells. Rheum Dis Clin North Am 2004, 30:473-486, viii.

12. Scott RS, McMahon EJ, Pop SM, Reap EA, Caricchio R, Cohen PL, Earp HS, Matsushima GK: Phagocytosis and clearance of apoptotic cells is mediated by MER. Nature 2001, 411:207-211.

13. Lemke G, Rothlin CV: Immunobiology of the TAM receptors. Nat Rev Immunol 2008, 8:327-336.

14. Cohen PL, Caricchio R, Abraham V, Camenisch TD, Jennette JC, Roubey RA, Earp HS, Matsushima G, Reap EA: Delayed apoptotic cell clearance and lupus-like autoimmunity in mice lacking the c-mer membrane tyrosine kinase. J Exp Med 2002, 196:135-140.

15. Lu Q, Lemke G: Homeostatic regulation of the immune system by receptor tyrosine kinases of the Tyro 3 family. Science 2001, 293:306-311.

16. Rothlin CV, Ghosh S, Zuniga El, Oldstone MB, Lemke G: TAM receptors are pleiotropic inhibitors of the innate immune response. Cell 2007 , 131:1124-1136.

17. Wallet MA, Flores RR, Wang Y, Yi Z, Kroger CJ, Mathews CE, Earp HS, Matsushima G, Wang B, Tisch R: MerTK regulates thymic selection of autoreactive T cells. Proc Natl Acad Sci U S A 2009, 106:4810-4815.

18. Hanayama R, Tanaka M, Miyasaka K, Aozasa K, Koike M, Uchiyama Y, Nagata S Autoimmune disease and impaired uptake of apoptotic cells in MFG-E8- 
deficient mice. Science 2004, 304:1147-1150

19. Asano K, Miwa M, Miwa K, Hanayama R, Nagase H, Nagata S, Tanaka M: Masking of phosphatidylserine inhibits apoptotic cell engulfment and induces autoantibody production in mice. J Exp Med 2004, 200:459-467.

20. Yamaguchi H, Takagi J, Miyamae T, Yokota S, Fujimoto T, Nakamura S, Ohshima S, Naka T, Nagata S: Milk fat globule EGF factor 8 in the serum of human patients of systemic lupus erythematosus. J Leukoc Biol 2008, 83:1300-1307.

21. Yamaguchi H, Fujimoto T, Nakamura S, Ohmura K, Mimori T, Matsuda F, Nagata S: Aberrant splicing of the milk fat globule-EGF factor 8 (MFG-E8) gene in human systemic lupus erythematosus. Eur I Immunol 2010, 40:1778-1785

22. Rahman ZS, Shao WH, Khan TN, Zhen Y, Cohen PL: Impaired apoptotic cell clearance in the germinal center by Mer-deficient tingible body macrophages leads to enhanced antibody-forming cell and germinal center responses. J Immunol 2010, 185:5859-5868.

23. Kobayashi N, Karisola P, Pena-Cruz V, Dorfman DM, Jinushi M, Umetsu SE, Butte MJ, Nagumo H, Chernova I, Zhu B, Sharpe AH, Ito S, Dranoff G, Kaplan GG, Casasnovas JM, Umetsu DT, Dekruyff RH, Freeman GJ: TIM-1 and TIM-4 glycoproteins bind phosphatidylserine and mediate uptake of apoptotic cells. Immunity 2007, 27:927-940.

24. Rodriguez-Manzanet R, Sanjuan MA, Wu HY, Quintana FJ, Xiao S, Anderson $A C$, Weiner HL, Green DR, Kuchroo VK: T and B cell hyperactivity and autoimmunity associated with niche-specific defects in apoptotic body clearance in TIM-4-deficient mice. Proc Natl Acad Sci U S A 2010, 107:8706-8711.

25. Nakayama M, Akiba H, Takeda K, Kojima Y, Hashiguchi M, Azuma M, Yagita H, Okumura K: Tim-3 mediates phagocytosis of apoptotic cells and crosspresentation. Blood 2009, 113:3821-3830.

26. Peter C, Wesselborg S, Herrmann M, Lauber K: Dangerous attraction: phagocyte recruitment and danger signals of apoptotic and necrotic cells. Apoptosis 2010, 15:1007-1028

27. Abdulahad DA, Westra J, Limburg PC, Kallenberg CG, Bijl M: HMGB1 in systemic lupus erythematosus: its role in cutaneous lesions development. Autoimmun Rev 2010, 9:661-665.

28. Urbonaviciute V, Furnrohr BG, Meister S, Munoz L, Heyder P, De Marchis F, Bianchi ME, Kirschning C, Wagner H, Manfredi AA, Kalden JR, Schett G, Rovere-Querini P, Herrmann M, Voll RE: Induction of inflammatory and immune responses by HMGB1-nucleosome complexes: implications for the pathogenesis of SLE. J Exp Med 2008, 205:3007-3018.

29. Barkauskaite V, Ek M, Popovic K, Harris HE, Wahren-Herlenius M, Nyberg F: Translocation of the novel cytokine HMGB1 to the cytoplasm and extracellular space coincides with the peak of clinical activity in experimentally UV-induced lesions of cutaneous lupus erythematosus. Lupus 2007, 16:794-802.

30. Popovic K, Ek M, Espinosa A, Padyukov L, Harris HE, Wahren-Herlenius M, Nyberg F: Increased expression of the novel proinflammatory cytokine high mobility group box chromosomal protein 1 in skin lesions of patients with lupus erythematosus. Arthritis Rheum 2005, 52:3639-3645.

31. Hayashi A, Nagafuchi H, Ito I, Hirota K, Yoshida M, Ozaki S: Lupus antibodies to the HMGB1 chromosomal protein: epitope mapping and association with disease activity. Mod Rheumatol 2009, 19:283-292.

32. Nagahama M, Nomura S, Kanazawa S, Ozaki Y, Kagawa H, Fukuhara S: Significance of anti-oxidized LDL antibody and monocyte-derived microparticles in anti-phospholipid antibody syndrome. Autoimmunity 2003, 36:125-131

33. Dignat-Georg F, Camoin-Jau L, Sabatier F, Arnoux D, Anfosso F, Bardin N, Veit V, Combes V, Gentile S, Moal V, Sanmarco M, Sampol J: Endothelial microparticles: a potential contribution to the thrombotic complications of the antiphospholipid syndrome. Thromb Haemost 2004, 91:667-673.

34. Pisetsky DS, Lipsky PE: Microparticles as autoadjuvants in the pathogenesis of SLE. Nat Rev Rheumatol 2010, 6:368-372.

35. Antwi-Baffour S, Kholia S, Aryee YK, Ansa-Addo EA, Stratton D, Lange S, Inal JM: Human plasma membrane-derived vesicles inhibit the phagocytosis of apoptotic cells - possible role in SLE. Biochem Biophys Res Commun 2010, 398:278-283.

36. Nomura S, Ozaki Y, Ikeda Y: Function and role of microparticles in various clinical settings. Thromb Res 2008, 123:8-23.

37. Osumi K, Ozeki Y, Saito S, Nagamura Y, Ito H, Kimura Y, Ogura H, Nomura S: Development and assessment of enzyme immunoassay for plateletderived microparticles. Thromb Haemost 2001, 85:326-330.
38. Neeli I, Dwivedi N, Khan S, Radic M: Regulation of extracellular chromatin release from neutrophils. J Innate Immun 2009, 1:194-201.

39. Hakkim A, Furnrohr BG, Amann K, Laube B, Abed UA, Brinkmann V, Herrmann $M$, Voll RE, Zychlinsky A: Impairment of neutrophil extracellular trap degradation is associated with lupus nephritis. Proc Natl Acad Sci U S A 2010, 107:9813-9818.

40. Bennett L, Palucka AK, Arce E, Cantrell V, Borvak J, Banchereau J, Pascual V: Interferon and granulopoiesis signatures in systemic lupus erythematosus blood. J Exp Med 2003, 197:711-723.

41. Schnabel A, Csernok E, Isenberg DA, Mrowka C, Gross WL: Antineutrophil cytoplasmic antibodies in systemic lupus erythematosus. Prevalence, specificities, and clinical significance. Arthritis Rheum 1995, 38:633-637.

42. Cairns AP, Crockard AD, McConnell JR, Courtney PA, Bell AL: Reduced expression of CD44 on monocytes and neutrophils in systemic lupus erythematosus: relations with apoptotic neutrophils and disease activity. Ann Rheum Dis 2001, 60:950-955.

43. Macanovic M, Lachmann PJ: Measurement of deoxyribonuclease I (DNase) in the serum and urine of systemic lupus erythematosus (SLE)-prone NZB/ NZW mice by a new radial enzyme diffusion assay. Clin Exp Immunol 1997, 108:220-226

44. Fenton K, Fismen S, Hedberg A, Seredkina N, Fenton C, Mortensen ES, Rekvig OP: Anti-dsDNA antibodies promote initiation, and acquired loss of renal Dnase1 promotes progression of lupus nephritis in autoimmune (NZBxNZW)F1 mice. PLoS One 2009, 4:e8474.

45. Napirei M, Karsunky H, Zevnik B, Stephan H, Mannherz HG, Moroy T: Features of systemic lupus erythematosus in Dnase1-deficient mice. Nat Genet 2000, 25:177-181.

46. Chitrabamrung S, Rubin RL, Tan EM: Serum deoxyribonuclease I and clinical activity in systemic lupus erythematosus. Rheumatol Int 1981, 1:55-60.

47. Yasutomo K, Horiuchi T, Kagami S, Tsukamoto H, Hashimura C, Urushihara M, Kuroda Y: Mutation of DNASE1 in people with systemic lupus erythematosus. Nat Genet 2001, 28:313-314.

48. Davis JC, Manzi S, Yarboro C, Rairie J, McInnes I, Averthelyi D, Sinicropi D, Hale VG, Balow J, Austin H, Boumpas DT, Klippel JH: Recombinant human Dnase I (rhDNase) in patients with lupus nephritis. Lupus 1999, 8:68-76.

49. Lachmann PJ: Allergic reactions, connective tissue, and disease. Sci Basis Med Annu Rev 1967, 36-58.

50. Baumann I, Kolowos W, Voll RE, Manger B, Gaipl U, Neuhuber WL, Kirchner T, Kalden JR, Herrmann M: Impaired uptake of apoptotic cells into tingible body macrophages in germinal centers of patients with systemic lupus erythematosus. Arthritis Rheum 2002, 46:191-201.

51. Kluz J, Kopec W, Jakobsche-Policht U, Adamiec R: Circulating endothelial cells, endothelial apoptosis and soluble markers of endothelial dysfunction in patients with systemic lupus erythematosus-related vasculitis. Int Angio/ 2009, 28:192-201.

52. Emlen W, Niebur J, Kadera R: Accelerated in vitro apoptosis of lymphocytes from patients with systemic lupus erythematosus. J Immunol 1994, 152:3685-3692.

53. Midgley A, McLaren Z, Moots RJ, Edwards SW, Beresford MW: The role of neutrophil apoptosis in juvenile-onset systemic lupus erythematosus. Arthritis Rheum 2009, 60:2390-2401.

54. Caricchio R, McPhie L, Cohen PL: Ultraviolet B radiation-induced cell death: critical role of ultraviolet dose in inflammation and lupus autoantigen redistribution. J Immunol 2003, 171:5778-5786.

55. Reefman E, Kuiper H, Jonkman MF, Limburg PC, Kallenberg CG, Bijl M: Skin sensitivity to UVB irradiation in systemic lupus erythematosus is not related to the level of apoptosis induction in keratinocytes. Rheumatology (Oxford) 2006, 45:538-544.

56. Reefman E, de Jong MC, Kuiper H, Jonkman MF, Limburg PC, Kallenberg CG, Bijl M: Is disturbed clearance of apoptotic keratinocytes responsible for UVB-induced inflammatory skin lesions in systemic lupus erythematosus? Arthritis Res Ther 2006, 8:R156.

57. Papadaki HA, Boumpas DT, Gibson FM, Jayne DR, Axford JS, Gordon-Smith EC, Marsh JC, Eliopoulos GD: Increased apoptosis of bone marrow CD34+ cells and impaired function of bone marrow stromal cells in patients with systemic lupus erythematosus. Br J Haematol 2001, 115:167-174.

58. Tas SW, Quartier P, Botto M, Fossati-Jimack L: Macrophages from patients with SLE and rheumatoid arthritis have defective adhesion in vitro, while only SLE macrophages have impaired uptake of apoptotic cells. Ann Rheum Dis 2006, 65:216-221.

59. Bengtsson AA, Sturfelt G, Gullstrand B, Truedsson L: Induction of apoptosis 
in monocytes and lymphocytes by serum from patients with systemic lupus erythematosus - an additional mechanism to increased autoantigen load? Clin Exp Immunol 2004, 135:535-543.

60. Bengtsson AA, Gullstrand B, Truedsson L, Sturfelt G: SLE serum induces classical caspase-dependent apoptosis independent of death receptors. Clin Immunol 2008, 126:57-66.

61. McColl A, Bournazos S, Franz S, Perretti M, Morgan BP, Haslett C, Dransfield I: Glucocorticoids induce protein S-dependent phagocytosis of apoptotic neutrophils by human macrophages. J Immunol 2009, 183:2167-2175.

62. Suh CH, Hilliard BA, Li S, Merrill JT, Cohen PL: TAM receptor ligands in lupus: protein $\mathrm{S}$ but not Gas6 levels reflect disease activity in systemic lupus erythematosus. Arthritis Res Ther 2010, 12:R146.
63. Sarmiento LF, Munoz LE, Chirinos P, Bianco NE, Zabaleta-Lanz ME: Opsonization by anti-dsDNA antibodies of apoptotic cells in systemic lupus erythematosus. Autoimmunity 2007, 40:337-339.

64. Hargraves MM, Richmond H, Morton R: Presentation of two bone marrow elements; the tart cell and the L.E. cell. Mayo Clin Proc 1948, 23:25-28.

doi:10.1186/ar3206

Cite this article as: Shao W-H, Cohen PL: Disturbances of apoptotic cell

clearance in systemic lupus erythematosus. Arthritis Research \& Therapy 2011, 13:202. 